Research Article

\title{
Effects of Monthly Intramuscular High-Dose Vitamin D2 on Serum 25-Hydroxyvitamin $D$ and Immune Parameters in Very Elderly Chinese Patients with Vitamin D Deficiency
}

\author{
Pingda Bian $\mathbb{D}^{\mathbb{D}},{ }^{1}$ Xue Jin $\mathbb{D}^{\mathbb{C}},{ }^{2}$ and Zhangxuan Shou $\mathbb{C}^{3}$ \\ ${ }^{1}$ Department of Geriatrics, Zhejiang Provincial People's Hospital, Affiliated People's Hospital, Hangzhou Medical College, \\ Hangzhou, Zhejiang, China \\ ${ }^{2}$ Clinical Pharmacy Center, Department of Pharmacy, Zhejiang Provincial People's Hospital, Affiliated People's Hospital, \\ Hangzhou Medical College, Hangzhou, Zhejiang, China \\ ${ }^{3}$ Department of Pharmacy, The Second Affiliated Hospital of Zhejiang Chinese Medical University, Hangzhou, Zhejiang, China \\ Correspondence should be addressed to Zhangxuan Shou; 20214021@zcmu.edu.cn
}

Received 4 September 2021; Revised 2 October 2021; Accepted 7 October 2021; Published 18 October 2021

Academic Editor: Faustino R. Perez-Lopez

Copyright $\odot 2021$ Pingda Bian et al. This is an open access article distributed under the Creative Commons Attribution License, which permits unrestricted use, distribution, and reproduction in any medium, provided the original work is properly cited.

\begin{abstract}
Purpose. Vitamin D deficiency is highly prevalent among the very elderly and is associated with a wide variety of clinical conditions other than musculoskeletal diseases. This study aims to ascertain the efficacy and safety of high-dose intramuscular vitamin D2 in very elderly Chinese patients with vitamin D deficiency. Methods. Very elderly (aged 80 years or over) Chinese patients with vitamin D deficiency were recruited to receive monthly intramuscular injections of 600,000 IU vitamin D2 until their serum 25 -hydroxyvitamin D $(25(\mathrm{OH}) \mathrm{D})$ reached $\geq 30 \mathrm{ng} / \mathrm{mL}$. The serum levels of $25(\mathrm{OH}) \mathrm{D} 2,25(\mathrm{OH}) \mathrm{D} 3$, iPTH, BTMs, immune parameters, and other biochemical parameters were measured at baseline and one month after each dose. Results. Of the 30 very elderly Chinese patients who had been recruited into the study, 27 (90.0\%) had their vitamin D deficiency corrected, and $26(86.7 \%)$ reached vitamin D sufficiency. The mean time $( \pm S D)$ was $3.1( \pm 1.3)$ months for vitamin D deficiency to be corrected, and $6.1( \pm 0.8)$ months for vitamin D sufficiency to be reached. The mean $( \pm \mathrm{SD})$ serum level of $25(\mathrm{OH}) \mathrm{D} 2 \mathrm{increased}$ from $0.69( \pm 1.51) \mathrm{ng} / \mathrm{mL}$ to $29.07( \pm 5.68) \mathrm{ng} / \mathrm{mL}$, while the mean $( \pm \mathrm{SD})$ serum level of 25(OH)D3 decreased from $9.82( \pm 2.75)$ $\mathrm{ng} / \mathrm{mL}$ to $5.30( \pm 3.09) \mathrm{ng} / \mathrm{mL}$ (both $P<0.001)$. The total T cells in serum remained unchanged $(P>0.05)$, and the CD4 and B cells $(\mathrm{CD} 19+)$ were increased significantly (both $P<0.05)$. In addition, no significant change was observed in the serum levels of iPTH and BTMs. Conclusion. Monthly intramuscular injection of 600,000 IU vitamin D2 is an effective and safe dosing regimen to reach vitamin $\mathrm{D}$ sufficiency and enhances immune function in the very elderly Chinese patients with vitamin $\mathrm{D}$ deficiency.
\end{abstract}

\section{Introduction}

Vitamin D deficiency, which is defined as a serum level of 25 -hydroxyvitamin $\mathrm{D}(25(\mathrm{OH}) \mathrm{D})$ below $20 \mathrm{ng} / \mathrm{mL}$ [1], is an ever-increasing health concern globally. In addition to musculoskeletal diseases such as muscle weakness, osteomalacia, osteoporosis, and fractures, it has been supposed to associate with an increased risk for a wide variety of clinically relevant conditions in adults such as chronic obstructive pulmonary disease (COPD) [2], acute respiratory distress syndrome (ARDS) [3], COVID-19 [4], infectious diseases
$[5,6]$, diabetes mellitus [7, 8], and autoimmune diseases [9]. On the other hand, vitamin $\mathrm{D}$ supplementation has been reported to accelerate inflammation resolution in hospitalized AECOPD patients [10], reduce mortality in mechanically ventilated patients [11], prevent acute respiratory tract infections [12], etc. Because of insufficient sunlight exposure, decreased function of the skin to synthesize vitamin $\mathrm{D}$ diminished intestinal absorption and/or dietary intake of vitamin $\mathrm{D}$, and vitamin $\mathrm{D}$ deficiency is widespread in the elderly [13]. As for the very elderly (aged 80 years and over), the prevalence of vitamin D deficiency 
was $65.7 \%$ among 367 Belgian [14], 75.8\% among 1324 Chinese [15], and even as high as $89.5 \%$ among 153 Lithuanians [16].

A serum level of $25(\mathrm{OH}) \mathrm{D} \geq 30 \mathrm{ng} / \mathrm{ml}$ is generally considered vitamin D sufficiency in adults [1]. In addition to increasing sun exposure and dietary intake of vitamin D-rich foods, oral intake and intramuscular injection of vitamin $\mathrm{D}$ pharmaceutical preparations are two major routes to reach this target [17]. Daily intake of low-dose vitamin D often needs a long period to reach target vitamin D status, while maintaining long-term adherence is not easy [18]. As a result, dosing regimens with high vitamin $\mathrm{D}$ doses at less frequent intervals have been proposed to improve patient compliance and obtain desired intervention outcomes [19]. Some studies demonstrated that intramuscular high-dose vitamin $\mathrm{D}$ is an effective approach to vitamin $\mathrm{D}$ sufficiency $[20,21]$, and that intramuscular administration is more effective than oral intake in the long term [22].

As we all know, there are two forms of vitamin D in humans. Vitamin D2, also known as ergocalciferol, is entirely obtained from dietary sources such as mushrooms. Vitamin D3, also known as cholecalciferol, is the major source of the human body's requirements for vitamin D [23]. It is mainly derived from dermal synthesis by the action of ultraviolet $\mathrm{B}$ (UVB) radiation on 7dehydrocholesterol (7DHC) to generate previtamin D3, which further undergoes a slow thermal isomerization to form vitamin D3 [24]. Vitamin D is hydroxylated at C-25 in the liver to produce $25(\mathrm{OH}) \mathrm{D}$, with the latter being further hydroxylated at $\mathrm{C}-1$ in the kidney to form $1,25(\mathrm{OH}) 2 \mathrm{D}$, the functional, hormonally active forms of vitamin D. Both vitamin D2 and vitamin D3 injections are suggested for the treatment and prevention of vitamin $\mathrm{D}$ deficiency [1]. Vitamin D3 injection, however, is not always commercially available as a pharmaceutical preparation [25]. Thus far, studies regarding intramuscular high-dose vitamin D supplementation have focused more on vitamin D3 $[20,21]$ than on vitamin D2 $[26,27]$, with the latter being evaluated only for the outcome of a single dose. Furthermore, there has been no common agreement worldwide to define a standard dose of vitamin D2 injection for the treatment and prevention of vitamin $D$ deficiency. Especially, the efficacy and safety of monthly intramuscular injection of high-dose vitamin D2 to reach vitamin D sufficiency in very elderly Chinese patients have not been elucidated.

This study was designed to ascertain the time needed to correct vitamin $\mathrm{D}$ deficiency and to reach vitamin $\mathrm{D}$ sufficiency in very elderly Chinese patients with monthly intramuscular injections of $600,000 \mathrm{IU}$ vitamin D2. The effects of this intervention on serum levels of iPTH, BTMs, immune parameters, and other biomedical parameters were also examined.

\section{Materials and Methods}

2.1. Study Design. All qualified patients were given monthly intramuscular injections of $600,000 \mathrm{IU}$ vitamin D2 (vitamin D2 injection, 200,000 IU/1 mL; Jiangxi Gannan
Pharmaceutical, Ganzhou, China) into the deltoid muscle of the upper arm. They were subjected to measurement of serum levels of $25(\mathrm{OH}) \mathrm{D} 2,25(\mathrm{OH}) \mathrm{D} 3$, iPTH, BTMs, immune parameters, and other biomedical parameters at baseline and one month after each shot. All participants were asked to have adequate fluid intake, take regular outdoor activities as usual, and receive about 20 minutes of sunlight exposure per day if weather permits during the study.

2.2. Subjects. From December 2020 to June 2021, very elderly Chinese patients with vitamin D deficiency, who were hospitalized in three 70-bed geriatrics wards for older cadres, Wangjiangshan Branch, Zhejiang Provincial People's Hospital, were recruited into the study. Exclusion criteria: (i) patients with hypoparathyroidism, hypercalcaemia, or hypercalciuria; (ii) with severe hepatic or renal dysfunction, moderate to severe cognitive dysfunction, or advanced malignancy; (iii) on antiosteoporosis agents such as bisphosphonates and teriparaptide; (iv) receiving potent enzyme inducers of vitamin $\mathrm{D}$ metabolism such as phenytoin, phenobarbital, carbamazepine, and rifampin; (v) taking calcium and/or vitamin $\mathrm{D}$ supplements, active forms of vitamin D or analogues. Each participant was asked to complete a questionnaire for collecting information on age, gender, height, weight, medical history, medication history, and status of vitamin D supplementation. The comorbidities they had were verified in accordance with the guidelines for specific diseases.

2.3. Sample Collection. All participants fasted overnight before scheduled sample collection. Venous blood was drawn right before the first dose of injection (baseline) and one month after each dose. Blood samples were centrifuged at room temperature to separate serum, assayed immediately, or stored at $-80^{\circ} \mathrm{C}$ until assay.

2.4. Measurement of Serum Levels of 25(OH)D2, 25(OH)D3, $i P T H$, and BTMs. Serum levels of 25(OH)D2 and 25(OH) D3 were measured by LC/MS/MS on an AB SCIEX Triple Quad $4500 \mathrm{MD}^{\mathrm{TM}} \mathrm{LC} / \mathrm{MS} / \mathrm{MS}$. Serum samples were mixed with $\mathrm{ZnSO}_{4}$ solution (protein precipitant), 25(OH)D2-IS, and 25(OH)D3-IS (internal standard) on a 96-well plate and rotated at $600 \mathrm{rpm}$ for 10 minutes. After being centrifuged at $4000 \mathrm{rpm}$ for 5 minutes, they were analyzed by using the HPLC/MS/MS system in the atmospheric pressure chemical ionization (APCI) mode and multiple reaction monitor $(\mathrm{MRM})$ mode. The limits of detection were both $0.01 \mathrm{ng} / \mathrm{mL}$ for $25(\mathrm{OH}) \mathrm{D} 2$ and $25(\mathrm{OH}) \mathrm{D} 3$. The intra- and interassay coefficients of variation (CV) were both less than $15 \%$ for $25(\mathrm{OH}) \mathrm{D} 2$ and $25(\mathrm{OH}) \mathrm{D} 3$. Total $25(\mathrm{OH}) \mathrm{D}$ levels were calculated as the sum of $25(\mathrm{OH}) \mathrm{D} 2$ and $25(\mathrm{OH}) \mathrm{D} 3$. Serum levels of iPTH, beta-crosslaps (beta-CTx), procollagen type I $\mathrm{N}$-terminal propeptide (P1NP), and total osteocalcin (OC) were measured with electrochemiluminescence immunoassay on an automatic device (Roche cobas e 601 Automated Analyzer, Roche Diagnostics, Tokyo, Japan). The intra- and 
interassay CVs were $1.22-2.44 \%$ and $1.91-2.61 \%$ for iPTH, $1.48-2.72 \%$ and $2.06-3.26 \%$ for beta-CTx, $1.85-3.06 \%$ and $2.41-4.00 \%$ for P1NP, and $1.01-2.21 \%$ and $1.56-3.56 \%$ for OC, respectively.

\subsection{Measurement of Serum Biochemical Parameters.} Serum levels of calcium, phosphorus, urea nitrogen, creatinine, total bilirubin, aspartate transaminase (AST), alanine transaminase (ALT), and gamma-glutamyl transpeptidase (GGT) were determined with standard methods on an automatic biochemistry analyzer (HITACHI 7600-010 Automatic Analyzer, Hitachi High-Technologies, Tokyo, Japan). The intra- and interassay CVs were $1.22-1.95 \%$ and $1.56-1.99 \%$ for calcium, $0.81-1.67 \%$ and $1.08-1.65 \%$ for phosphorus, $0.99-2.89 \%$ and $1.35-2.68 \%$ for urea nitrogen, $1.45-2.77 \%$ and $1.61-2.64 \%$ for creatinine, $0.71-1.94 \%$ and $1.19-1.59 \%$ for total bilirubin, $0.82-1.92 \%$ and $1.16-1.99 \%$ for AST, $0.81-1.86 \%$ and $1.04-1.94 \%$ for ALT, and $0.75-0.88 \%$ and $1.17-1.82 \%$ for GGT.

2.6. Measurement of Serum Immune Parameters. Serum immune function parameters including total T cells (CD3+), B cells (CD19+), CD4, and CD8 were monitored by flow cytometry (Navios, Beckman Coulter) with a detection CV $\leq 2 \%$.

2.7. Efficacy Observation. The primary efficacy endpoint was the time needed to reach serum levels of $25(\mathrm{OH}) \mathrm{D} \geq 30 \mathrm{ng} /$ $\mathrm{mL}$ in the very elderly Chinese patients with monthly intramuscular injections of 600,000 IU vitamin D2. The secondary efficacy endpoint was the effects of this dosing regimen on the serum levels of iPTH, BTMs, and immune function parameters.

2.8. Safety Observation. The safety profile of this dosing regimen was assessed in terms of changes in biochemical parameters and adverse drug reactions (ADRs) reported by the subjects. All participants were asked to report potential ADRs such as anorexia, diarrhea, constipation, nausea, vomiting, bone pain, drowsiness, continuous headache, irregular heartbeat, loss of appetite, muscle and joint pain, frequent urination, excessive thirst, weakness, nervousness, and itching.

2.9. Ethical Approval. The study was performed in accordance with the principles outlined in the Declaration of Helsinki and was approved by the Medical Ethics Committee of Zhejiang Provincial People's Hospital. All the participants provided their written informed consent for the study and were free to withdraw from the study at any time.

2.10. Statistical Analysis. Sample size was calculated with an expected parameter estimate based on a pilot study conducted in our department, and the minimum sample size required was 31 patients in each study group within a $95 \%$ confidence and $80 \%$ power. All statistical analyses were performed by using SPSS 17.0 for Windows (SPSS Inc., IBM Company, Chicago, USA). Continuous variables were expressed as mean \pm standard deviation (SD) and tested for normality before comparisons. Paired $t$-test or Wilcoxon rank sum test was performed for between-time comparisons depending on whether normality assumption was met. A $P$ value less than 0.05 was considered of statistical significance. Continuous variables were tested for normality.

\section{Results}

3.1. Baseline Demographic and Clinical Characteristics of the Participants. A total of 30 very elderly Chinese patients were recruited into the study. Out of them, 27 (90.0\%) patients had their vitamin D deficiency corrected, 26 (86.7\%) patients reached vitamin sufficiency and completed the study. The data from these 26 patients were used to analyze the effects of the intervention. All variables compared were normally distributed. The baseline characteristics of the subjects are presented in Table 1 . The mean $( \pm \mathrm{SD})$ serum level of $25(\mathrm{OH})$ $\mathrm{D}$ at baseline was $10.42( \pm 2.79) \mathrm{ng} / \mathrm{mL}$ in the participants who completed the study.

3.2. Changes in Serum Levels of 25(OH)D2, 25(OH)D3, iPTH, BTMs, and Biochemical Parameters. Changes in serum levels of $25(\mathrm{OH}) \mathrm{D}, 25(\mathrm{OH}) \mathrm{D} 3$, iPTH, BTMs, and biochemical parameters after intervention are presented in Table 2 . The mean $( \pm$ SD) serum level of $25(\mathrm{OH}) \mathrm{D}$ increased from 10.42 $( \pm 2.79) \mathrm{ng} / \mathrm{mL}$ to $34.36( \pm 4.63) \mathrm{ng} / \mathrm{mL}(P<0.001)$. Specifically, the mean $( \pm \mathrm{SD})$ serum level of $25(\mathrm{OH}) \mathrm{D} 2$ increased from $0.69( \pm 1.51) \mathrm{ng} / \mathrm{mL}$ to $29.07( \pm 5.68) \mathrm{ng} / \mathrm{mL}$, while the mean $( \pm \mathrm{SD})$ serum level of $25(\mathrm{OH}) \mathrm{D} 3$ decreased from 9.82 $( \pm 2.75) \mathrm{ng} / \mathrm{mL}$ to $5.30 \quad( \pm 3.09) \mathrm{ng} / \mathrm{mL}$ (both $P<0.001)$, which was illustrated by the changes in the patients who received six shots of vitamin D2 injection (Figure 1). There was no significant change observed in serum levels of iPTH, beta-CTx, P1NP, OC, calcium, phosphorus, urea nitrogen, creatinine, total bilirubin, AST, ALT, and GGT.

\subsection{Changes in Serum Levels of Immune Function Parameters.} As shown in Table 3, after intervention, the serum level (mean $\pm \mathrm{SD}$ ) of total $\mathrm{T}$ cells $(\mathrm{CD} 3+)$ remained unchanged $(P>0.05)$, and the levels (mean \pm SD) of CD4 and B cells (CD19+) were increased significantly (both $P<0.05$ ), while the level (mean $\pm \mathrm{SD}$ ) of CD8 decreased as the result of increased CD4 $(P<0.05)$.

\subsection{Time Needed to Correct Vitamin D Deficiency and Reach} Vitamin D Sufficiency. With monthly intramuscular injections of 600,000 IU vitamin D2, we found the time (mean $\pm \mathrm{SD}$, range) was $3.1 \pm 1.3(1-6)$ months to correct vitamin $\mathrm{D}$ deficiency and $6.1 \pm 0.8(5-8)$ months to reach vitamin $\mathrm{D}$ sufficiency in the very elderly Chinese patients with vitamin $\mathrm{D}$ deficiency. The number of patients and the time they spent to reach vitamin D sufficiency are detailed in Figure 2 . 
TABLE 1: Baseline demographic and clinical characteristics of participants.

\begin{tabular}{lcc}
\hline Parameters & Recruited & Completed \\
\hline Number of participants & 30 & 26 \\
Man/women, $n$ & $25 / 5$ & $22 / 4$ \\
Mean age \pm SD (range), years & $89.60 \pm 2.92(84-95)$ & $89.35 \pm 2.86(84-95)$ \\
$\mathrm{BMI}, \mathrm{kg} / \mathrm{m}^{2}$ & $23.18 \pm 3.17$ & $22.21 \pm 3.23$ \\
$25(\mathrm{OH}) \mathrm{D}, \mathrm{ng} / \mathrm{mL}$ & $10.39 \pm 2.72(1.24-14.32)$ & $10.42 \pm 2.79(1.24-17.20)$ \\
$25(\mathrm{OH}) \mathrm{D} 2, \mathrm{ng} / \mathrm{mL}$ & $0.65 \pm 1.41(0.02-6.13)$ & $0.69 \pm 1.51(0.02-6.13)$ \\
$25(\mathrm{OH}) \mathrm{D} 3, \mathrm{ng} / \mathrm{mL}$ & $9.82 \pm 2.69(1.22-14.30)$ & $9.82 \pm 2.75(1.22-14.30)$ \\
Comorbidities, $n$ & - & - \\
Hypertension & 28 & 24 \\
Type 2 diabetes mellitus & 9 & 8 \\
Chronic gastritis & 9 & 8 \\
Chronic obstructive pulmonary disease & 12 & 10 \\
\hline
\end{tabular}

TABLE 2: Changes in serum levels of 25(OH)D2, 25(OH)D3, iPTH, BTMs, and biochemical parameters after intervention.

\begin{tabular}{|c|c|c|c|c|}
\hline Parameters & Baseline & End of intervention & $t$ & $P$ \\
\hline $25(\mathrm{OH}) \mathrm{D}, \mathrm{ng} / \mathrm{mL}$ & $10.42 \pm 2.79$ & $34.36 \pm 4.63$ & -21.227 & $\leq 0.001$ \\
\hline $25(\mathrm{OH}) \mathrm{D} 2, \mathrm{ng} / \mathrm{mL}$ & $0.69 \pm 1.51$ & $29.07 \pm 5.68$ & -26.898 & $\leq 0.001$ \\
\hline $25(\mathrm{OH}) \mathrm{D} 3, \mathrm{ng} / \mathrm{mL}$ & $9.82 \pm 2.75$ & $5.30 \pm 3.09$ & 6.488 & $\leq 0.001$ \\
\hline $\mathrm{iPTH}, \mathrm{pg} / \mathrm{mL}$ & $37.59 \pm 20.65$ & $37.12 \pm 21.46$ & 0.245 & 0.808 \\
\hline Beta-CTx, ng/mL & $0.38 \pm 0.21$ & $0.35 \pm 0.20$ & 1.014 & 0.320 \\
\hline $\mathrm{P} 1 \mathrm{NP}, \mathrm{ng} / \mathrm{mL}$ & $38.21 \pm 17.53$ & $37.79 \pm 20.82$ & 0.124 & 0.902 \\
\hline $\mathrm{OC}, \mathrm{ng} / \mathrm{mL}$ & $12.91 \pm 5.32$ & $12.23 \pm 5.27$ & 1.395 & 0.175 \\
\hline Calcium, mmol/L & $2.30 \pm 0.14$ & $2.34 \pm 0.11$ & -1.908 & 0.068 \\
\hline Phosphorus, mmol/L & $0.94 \pm 0.14$ & $0.93 \pm 0.14$ & 0.580 & 0.567 \\
\hline Urea nitrogen, $\mu \mathrm{mol} / \mathrm{L}$ & $7.98 \pm 2.51$ & $7.90 \pm 2.88$ & 0.204 & 0.840 \\
\hline Creatinine, $\mu \mathrm{mol} / \mathrm{L}$ & $97.38 \pm 18.08$ & $101.12 \pm 20.39$ & -1.534 & 0.138 \\
\hline Total bilirubin, $\mu \mathrm{mol} / \mathrm{L}$ & $10.21 \pm 5.88$ & $10.89 \pm 7.20$ & -1.226 & 0.232 \\
\hline AST, IU/L & $17.77 \pm 10.01$ & $17.15 \pm 9.93$ & 0.324 & 0.749 \\
\hline $\mathrm{ALT}, \mathrm{IU} / \mathrm{L}$ & $21.23 \pm 6.16$ & $21.81 \pm 8.64$ & -0.423 & 0.676 \\
\hline GGT, IU/L & $29.31 \pm 8.62$ & $29.38 \pm 6.79$ & -0.027 & 0.979 \\
\hline
\end{tabular}

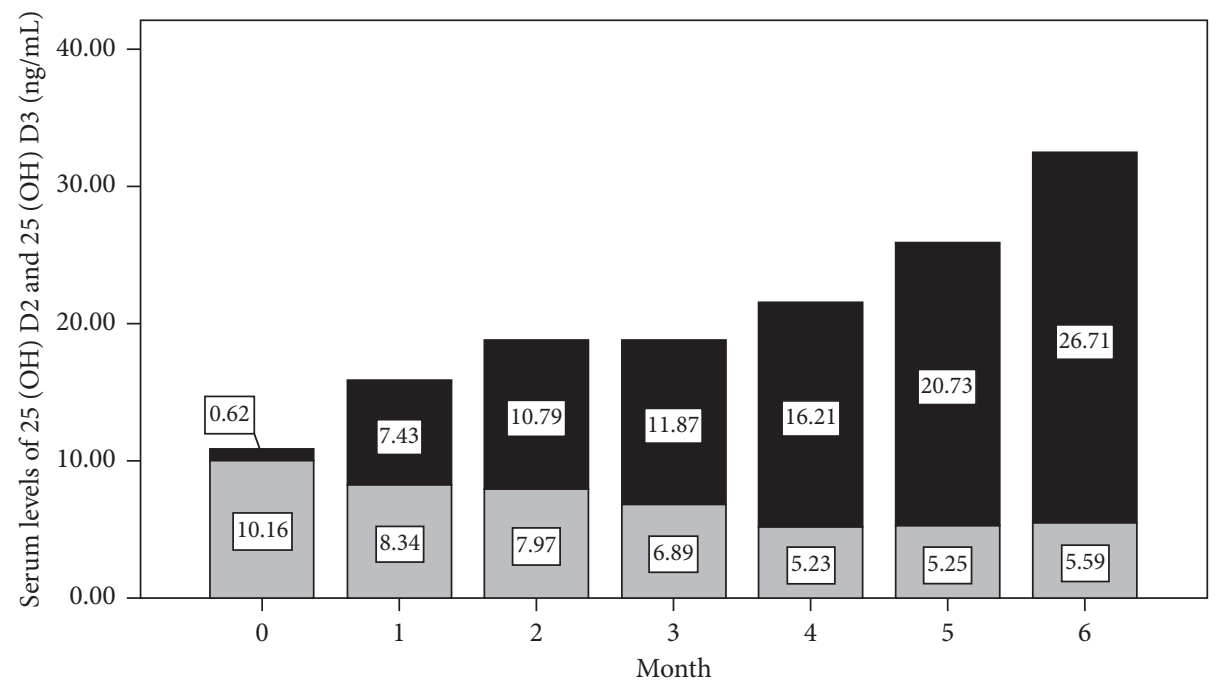

$25(\mathrm{OH}) \mathrm{D} 2$

$25(\mathrm{OH}) \mathrm{D} 3$

Figure 1: Changes in serum levels of $25(\mathrm{OH}) \mathrm{D} 2$ and $25(\mathrm{OH}) \mathrm{D} 3$ in patients who received six shots of vitamin D2. 
TABLE 3: Changes in serum immune function parameters after intervention.

\begin{tabular}{lcccc}
\hline Parameters & Baseline & $\begin{array}{c}\text { End of } \\
\text { intervention }\end{array}$ & $t$ & $P$ \\
\hline $\begin{array}{l}\text { Total T cells } \\
\text { (CD3+) }\end{array}$ & $68.27 \pm 13.00$ & $68.13 \pm 11.41$ & 0.115 & 0.910 \\
B cells (CD19+) & $5.42 \pm 3.34$ & $7.91 \pm 5.27$ & -3.556 & 0.002 \\
CD4 & $39.57 \pm 9.24$ & $42.07 \pm 9.07$ & -2.295 & 0.030 \\
CD8 & $25.83 \pm 13.11$ & $23.33 \pm 12.50$ & 4.521 & $\leq 0.001$ \\
\hline
\end{tabular}

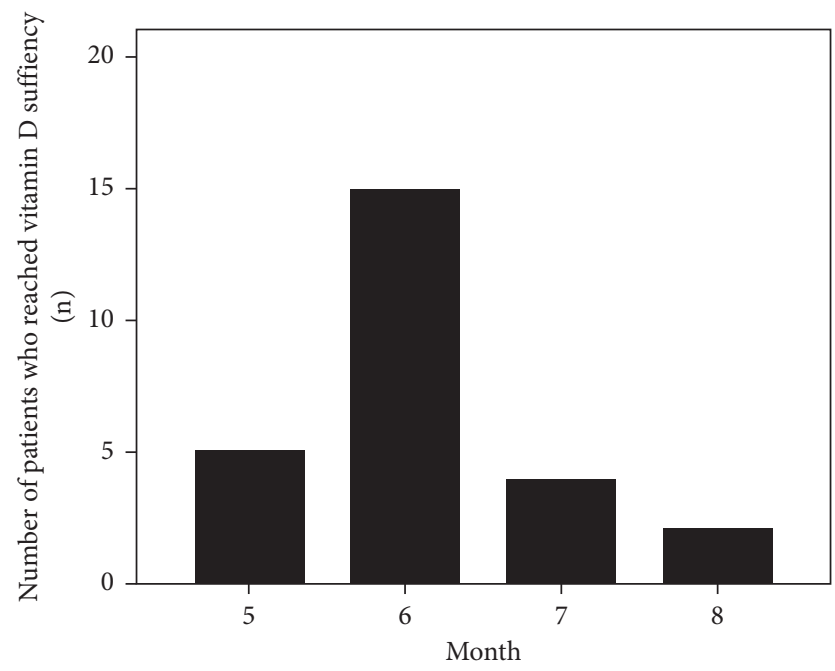

FIGURE 2: Number of patients and the time spent to reach vitamin D sufficiency.

3.5. Adverse Drug Reactions. The changes in biochemical parameters after the intervention are shown in Table 1. The highest serum level of $25(\mathrm{OH}) \mathrm{D}$ was $44.71 \mathrm{ng} / \mathrm{mL}$, which was far less than the concentration $(100 \mathrm{ng} / \mathrm{mL})$ considered perfectly safe [1]. There were no hypercalcaemia, hyperphosphatemia, and no hypoparathyroidism observed in all participants. In addition to one case of swelling and lump at the injection site, which resolved after hot compress therapy, there was no abovementioned adverse drug reaction reported by the participants.

\section{Discussion}

Vitamin D, in its most hormonally active form of $1 \alpha, 25$ dihydroxyvitamin $\mathrm{D}(1 \alpha, 25(\mathrm{OH}) 2 \mathrm{D})$, has been associated with a myriad of functions other than maintaining musculoskeletal health through regulation of calcium and phosphorus homeostasis. Some studies have demonstrated that most peripheral tissues have the capacity to convert $25(\mathrm{OH}) \mathrm{D}$ to $1 \alpha, 25(\mathrm{OH}) 2 \mathrm{D}$ to meet the local needs in a paracrine way [28], which largely depends on the availability of circulating 25(OHD). Therefore, to sustain sufficient serum 25(OH)D has important clinical relevance.

Solar exposure becomes increasingly limited among the very elderly people, which is the direct result of lifestyle changes such as increased clothing and decreased outdoor activities. Even worse, the capacity of the skin to synthesize vitamin D3 decreases as the human body ages, leading to insufficient endogenous vitamin D production [29]. It was reported that the amount of dermal-origin vitamin $\mathrm{D}$ in a 70 -year-old person is only one-fourth of that synthesized in a 20-year-old person [30]. In addition, the ability of the intestine to absorb dietary vitamin $\mathrm{D}$ in the very elderly was also presumably diminished [31]. As a result, supplementation of exogenous vitamin $\mathrm{D}$ by intramuscular injection would be a pragmatic option for the treatment and prevention of vitamin deficiency among the very elderly.

In spite of the continued controversy regarding the relative effectiveness of vitamin D2 and D3 on raising serum levels of 25(OH)D [32, 33], vitamin D2 has been used for more than 50 years for the treatment and prevention of vitamin $\mathrm{D}$ deficiency [25]. 25(OH)D2, one of the intermediates of the most bioactive vitamin $\mathrm{D}$ metabolites $(1,25(\mathrm{OH})$ 2D), was found not to be bound as tightly to vitamin D binding protein (DBP) as $25(\mathrm{OH}) \mathrm{D} 3$ [34], leading to a higher free level of 25(OH)D2 compared to that of $25(\mathrm{OH})$ D3 [35]. From this point of view, vitamin D2 would be theoretically more biologically effective than vitamin D3 because the free type of $25(\mathrm{OH}) \mathrm{D}$ is thought to have the most physiologic effects [25].

$\mathrm{Xu}$ and colleagues found that, after a single high dose of intramuscular vitamin $\mathrm{D} 2$, the level of $25(\mathrm{OH}) \mathrm{D} 2$ increased slowly and plateaued for 12 weeks [27]. In general, a single high-dose of oral vitamin D2 is initially more effective than the equivalent intramuscular one in increasing serum $25(\mathrm{OH}) \mathrm{D}$, while the latter can produce a slower but more long-lasting increase [22,33]. A single intramuscular dose of 300,000 IU vitamin D2 was shown not to effectively correct vitamin D deficiency [26, 33]. Moreover, researchers found that a single intramuscular dose of 600,000 IU vitamin D2 could correct vitamin D deficiency, but it could not reach vitamin D sufficiency [27]. Taking all this into account, we adopted a monthly intramuscular $600,000 \mathrm{IU}$ vitamin D2 to reach vitamin $\mathrm{D}$ sufficiency in the very elderly Chinese people with vitamin $\mathrm{D}$ deficiency. We found in our current study that the mean $( \pm \mathrm{SD})$ serum level of $25(\mathrm{OH}) \mathrm{D}$ was elevated from $10.42( \pm 2.79) \mathrm{ng} / \mathrm{mL}$ at baseline to 34.36 $( \pm 4.63) \mathrm{ng} / \mathrm{mL}$ after the intervention. The mean $( \pm \mathrm{SD})$ time was $3.1( \pm 1.3)$ months to correct vitamin D deficiency and $6.1( \pm 0.8)$ months to reach vitamin D sufficiency in the very elderly Chinese patients with vitamin D deficiency.

Vitamin D2 treatment has been associated with a decrease in the serum level of $25(\mathrm{OH}) \mathrm{D} 3$ [27]. It was postulated to be the response to increased total $25(\mathrm{OH}) \mathrm{D}$ following vitamin $\mathrm{D} 2$ supplementation because a decrease in the serum level of $25(\mathrm{OH}) \mathrm{D} 2$ was also observed after vitamin D3 treatment [36]. We found in our present study that, in parallel with the rapidly increasing of serum $25(\mathrm{OH}) \mathrm{D} 2$, serum $25(\mathrm{OH}) \mathrm{D} 3$ decreased gradually, which partially offsets the net increase in total $25(\mathrm{OH}) \mathrm{D}$. Intriguingly, the changes in serum levels of 25(OH)D2 after vitamin D3 intervention and 25(OH)D3 after vitamin D2 intervention were found to be similar in magnitude, signifying there would be a common regulatory mechanism [37].

iPTH and vitamin D are both involved in bone metabolism and have an inverse correlation [38]. iPTH 
concentrations are regarded as a functional parameter of vitamin D status [39] and are directly modulated and suppressed by $25(\mathrm{OH}) \mathrm{D}$ concentrations [32]. When vitamin $\mathrm{D}$ levels are low, a compensatory mechanism, which is known as secondary hyperparathyroidism, is trigged to stimulate the release of iPTH through an action on calciumsensing receptors located on parathyroid cells. High levels of serum iPTH are often observed in patients with insufficient vitamin $\mathrm{D}$, while vitamin $\mathrm{D}$ supplementation can decrease serum iPTH concentrations [38]. In contrast to previous reports that vitamin $\mathrm{D}$ at doses of $50,000 \mathrm{IU}$ orally, 200,000 IU or above intramuscularly reduced serum levels of iPTH $[17,27]$, we observed no significant change in serum levels of iPTH in very elderly Chinese patients after highdose intramuscular vitamin D2 intervention. This could be explained at least in part by the lower baseline iPTH serum levels observed in our present study [22]. A higher target $25(\mathrm{OH}) \mathrm{D}$ level may be needed to suppress the serum concentrations of iPTH in the very elderly patients.

$25(\mathrm{OH}) \mathrm{D}$ is converted to $1,25(\mathrm{OH}) 2 \mathrm{D}$ by the enzyme 1 alpha-hydroxylase in the kidneys, with the latter in turn increasing the intestinal absorption of calcium and phosphorous, stimulating bone resorption, and promoting reabsorption of calcium and phosphorous by renal tubules. This leads to a concern about elevated levels of calcium and BTMs when serum levels of 25(OH)D are enhanced. Despite vitamin D intoxication is extremely rare [25], supplementation of high-dose vitamin $\mathrm{D}$ is deemed to have the potential to cause toxicity, which is characterized by elevated serum levels of calcium and phosphorus [25]. A single intramuscular dose of 300,000 IU vitamin D has been considered well tolerated and safe [26]. Some studies also showed that a single dose of 300,000 IU or $600,000 \mathrm{IU}$ intramuscular vitamin D2 would not lead to hypercalcaemia $[26,27,33]$ and hyperphosphatemia [22]. Xu et al. found that a single dose of intramuscular vitamin D2 up to $600,000 \mathrm{IU}$ did not alter the serum levels of BTMs [27]. In our present study, the serum levels of calcium, phosphorus, and BTMs in the very elderly Chinese patients remained unchanged after they had received monthly intramuscular 600,000 IU vitamin D2 up to 8 months. Furthermore, during the whole study, none of the participants had reached a serum $25(\mathrm{OH})$ D concentration of $100 \mathrm{ng} / \mathrm{mL}$, which was considered perfectly safe [1].

Vitamin D receptor has been found on almost all cells of the immune system, which links vitamin $\mathrm{D}$ to immune function. Low circulating vitamin $\mathrm{D}$ was shown to be associated with impaired innate immune function [40]. We demonstrated in the current study that, with monthly intramuscular $600,000 \mathrm{IU}$ vitamin D2, CD4, one of the main immunoactive factors, was increased significantly in serum in the very elderly Chinese people. In addition, the serum level of B cells (CD19+) was also lifted significantly. These results suggest that vitamin $\mathrm{D}$ supplementation can improve cellular and humoral immune function in the very elderly people.

There are some limitations in our study. One is the relatively small sample size, which makes it a little less representative to depict the changes in serum levels of
25 $(\mathrm{OH}) \mathrm{D}$ and $\mathrm{iPTH}$ resulted from the intervention. The other one is the same dose of vitamin D2 for each single patient, which ignored the impact of body weight on increasing circulating 25(OH)D levels [33]. The last one is that the results were not adjusted for sun exposure and seasonal factor despite that they play a crucial role in the variation of serum $25(\mathrm{OH}) \mathrm{D}$ levels. Further welldesigned studies, which consider as many influential factors as possible, are warranted to identify an optimal and specific approach to correct vitamin D deficiency and reach vitamin $D$ sufficiency in the very elderly people.

To draw a conclusion, monthly intramuscular $600,000 \mathrm{IU}$ vitamin D2 is an effective and safe strategy to achieve vitamin D sufficiency and enhance immune function in the very elderly Chinese patients with vitamin $\mathrm{D}$ deficiency.

$\begin{array}{ll}\text { Abbreviations } \\ \text { 25(OH)D: } & \text { 25-hydroxyvitamin D } \\ \text { iPTH: } & \text { Intact parathyroid hormone } \\ \text { BTMs: } & \text { Bone turnover markers } \\ \text { beta-CTx: } & \text { Beta-crosslaps } \\ \text { P1NP: } & \text { Procollagen type I N-terminal propeptide } \\ \text { OC: } & \text { Osteocalcin } \\ \text { AST: } & \text { Aspartate transaminase } \\ \text { ALT: } & \text { Alanine transaminase } \\ \text { GGT: } & \text { Gamma-glutamyl transpeptidase } \\ \text { CV: } & \text { Coefficient of variation. }\end{array}$

\section{Data Availability}

The data that support the findings of this study are available from the corresponding author upon reasonable request.

\section{Ethical Approval}

The study was approved by the Medical Ethics Committee of Zhejiang Provincial People's Hospital.

\section{Consent}

All participants provided written informed consent.

\section{Conflicts of Interest}

The authors declare that they have no conflicts of interest.

\section{Authors' Contributions}

Pingda Bian and Xue Jin contributed equally to the manuscript. Zhangxuan Shou conceptualized the study and contributed to the reviewing, editing, and finalizing the manuscript. Pinda Bian contributed to methodology and investigation; Xue Jin contributed to data collection and analysis and writing of the original draft. All authors reviewed and approved the final manuscript. 


\section{Acknowledgments}

All authors would like to thank Mr. Ke Xu for his assistance with the description and acquirement of methodological data. This work was funded by grants from the Zhejiang Province Public Welfare Technology Application Research Project (no. LGF19H180014), Zhejiang Provincial Medicine and Healthcare Research Program (no. 2018KY214, 2018KY222, and 2021KY459), and the Research Project of Zhejiang Traditional Chinese Medicine Administration (no. 2018ZA008 and 2019ZA010).

\section{References}

[1] M. F. Holick, N. C. Binkley, H. A. Bischoff-Ferrari et al., "Evaluation, treatment, and prevention of vitamin D deficiency: an Endocrine Society clinical practice guideline," Journal of Clinical Endocrinology \& Metabolism, vol. 96, no. 7, pp. 1911-1930, 2011.

[2] K. S. Lokesh, S. K. Chaya, B. S. Jayaraj et al., "Vitamin D deficiency is associated with chronic obstructive pulmonary disease and exacerbation of COPD," The Clinical Respiratory Journal, vol. 15, no. 4, pp. 389-399, 2021.

[3] R. C. A. Dancer, D. Parekh, S. Lax et al., "Vitamin D deficiency contributes directly to the acute respiratory distress syndrome (ARDS)," Thorax, vol. 70, no. 7, pp. 617-624, 2015.

[4] P. Zemb, P. Bergman, C. A. Camargo Jr et al., "Vitamin D deficiency and the COVID-19 pandemic," Journal of Global Antimicrobial Resistance, vol. 22, pp. 133-134, 2020.

[5] S. B. Ali, D. Perdawood, R. Abdulrahman, D. A. Al Farraj, and N. A. Alkubaisi, "Vitamin D deficiency as a risk factor for urinary tract infection in women at reproductive age," Saudi Journal of Biological Sciences, vol. 27, no. 11, pp. 2942-2947, 2020.

[6] A. Kuwabara, N. Tsugawa, M. Ao, J. Ohta, and K. Tanaka, "Vitamin D deficiency as the risk of respiratory tract infections in the institutionalized elderly: a prospective 1-year cohort study," Clinical Nutrition ESPEN, vol. 40, pp. 309-313, 2020.

[7] X. Li, Y. Liu, Y. Zheng, P. Wang, and Y. Zhang, "The effect of vitamin $\mathrm{D}$ supplementation on glycemic control in type 2 diabetes patients: a systematic review and meta-analysis," Nutrients, vol. 10, no. 3, p. 375, 2018.

[8] C. Liu, J. Wang, Y. Wan et al., "Serum vitamin D deficiency in children and adolescents is associated with type 1 diabetes mellitus," Endocrine Connections, vol. 7, no. 12, pp. 1275-1279, 2018.

[9] J. Wang, S. Lv, G. Chen et al., "Meta-analysis of the association between vitamin $\mathrm{D}$ and autoimmune thyroid disease," $\mathrm{Nu}$ trients, vol. 7, no. 4, pp. 2485-2498, 2015.

[10] F. Dastan, J. Salamzadeh, M. H. Pourrashid, M. Edalatifard, and A. Eslaminejad, "Effects of high-dose vitamin D replacement on the serum levels of systemic inflammatory biomarkers in patients with acute exacerbation of chronic obstructive pulmonary disease," COPD: Journal of Chronic Obstructive Pulmonary Disease, vol. 16, no. 3-4, pp. 278-283, 2019.

[11] M. Miri, M. Kouchek, A. Rahat Dahmardeh, and M. Sistanizad, "Effect of high-dose vitamin D on suration of mechanical ventilation in ICU patients," Iranian Journal of Pharmaceutical Research, vol. 18, no. 2, pp. 1067-1072, 2019.

[12] A. R. Martineau, D. A. Jolliffe, R. L. Hooper et al., "Vitamin D supplementation to prevent acute respiratory tract infections: systematic review and meta-analysis of individual participant data," BMJ, vol. 356, Article ID i6583, 2017.

[13] H. Kweder and H. Eidi, "Vitamin D deficiency in elderly: risk factors and drugs impact on vitamin D status," Avicenna Journal of Medicine, vol. 8, no. 4, pp. 139-146, 2018.

[14] C. Matheï, G. Van Pottelbergh, B. Vaes, W. Adriaensen, D. Gruson, and J.-M. Degryse, "No relation between vitamin D status and physical performance in the oldest old: results from the Belfrail study," Age and Ageing, vol. 42, no. 2, pp. 186-190, 2013.

[15] Q. Xiao, M. Wu, J. Cui, M. Yuan, Y. Chen, and T. Zeng, "Plasma 25-hydroxyvitamin D level and the risk of frailty among Chinese community-based oldest-old: evidence from the CLHLS study," BMC Geriatrics, vol. 20, no. 1, p. 126, 2020.

[16] V. Alekna, J. Kilaite, A. Mastaviciute, and M. Tamulaitiene, "Vitamin D level and activities of daily living in octogenarians: cross-sectional study," Frontiers in Endocrinology, vol. 9, p. 326, 2018.

[17] M. Q. Masood, A. Khan, S. Awan et al., "Comparison of vitamin D replacement strategies with high-dose intramuscular or oral cholecalciferol: a prospective intervention study," Endocrine Practice, vol. 21, no. 10, pp. 1125-1133, 2015.

[18] L. Dalle Carbonare, M. Valenti, F. Del Forno, E. Caneva, and A. Pietrobelli, "Vitamin D: daily vs. monthly use in children and elderly-what is going on?" Nutrients, vol. 9, no. 7, p. 652, 2017.

[19] N. Binkley, D. Gemar, J. Engelke et al., "Evaluation of ergocalciferol or cholecalciferol dosing, 1,600 IU daily or 50,000 IU monthly in older adults," Journal of Clinical Endocrinology \& Metabolism, vol. 96, no. 4, pp. 981-988, 2011.

[20] A. H. Khan, D. K. Rohra, S. A. Saghir, S. K. Udani, R. Wood, and A. Jabbar, "Response of a single "mega intramuscular dose" of vitamin D on serum 25OHD and parathyroid hormone levels," Journal of the College of Physicians and Surgeons-Pakistan: JCPSP, vol. 22, no. 4, pp. 207-212, 2012.

[21] T. H. Diamond, K. W. Ho, P. G. Rohl, and M. Meerkin, "Annual intramuscular injection of a megadose of cholecalciferol for treatment of vitamin D deficiency: efficacy and safety data," Medical Journal of Australia, vol. 183, no. 1, pp. 10-12, 2005.

[22] C. Cipriani, E. Romagnoli, J. Pepe et al., "Long-term bioavailability after a single oral or intramuscular administration of 600,000 IU of ergocalciferol or cholecalciferol: implications for treatment and prophylaxis," Journal of Clinical Endocrinology \& Metabolism, vol. 98, no. 7, pp. 2709-2715, 2013.

[23] M. G. Kimlin, "Geographic location and vitamin D synthesis," Molecular Aspects of Medicine, vol. 29, no. 6, pp. 453-461, 2008.

[24] S. Christakos, P. Dhawan, A. Verstuyf, L. Verlinden, and G. Carmeliet, "Vitamin D: metabolism, molecular mechanism of action, and pleiotropic effects," Physiological Reviews, vol. 96, no. 1, pp. 365-408, 2016.

[25] M. F. Holick, "The vitamin D deficiency pandemic: approaches for diagnosis, treatment and prevention," Reviews in Endocrine and Metabolic Disorders, vol. 18, no. 2, pp. 153-165, 2017.

[26] P. Leventis and P. D. W. Kiely, "The tolerability and biochemical effects of high-dose bolus vitamin D2 and D3 supplementation in patients with vitamin D insufficiency," Scandinavian Journal of Rheumatology, vol. 38, no. 2, pp. 149-153, 2009.

[27] F. Xu, D. Dai, R. Sun et al., "Long-term bioavailability of single doses of intramuscular vitamin D2," Endocrine Practice, vol. 26, no. 11, pp. 1244-1254, 2020. 
[28] J. S. Adams and M. Hewison, "Extrarenal expression of the 25hydroxyvitamin D-1-hydroxylase," Archives of Biochemistry and Biophysics, vol. 523, no. 1, pp. 95-102, 2012.

[29] J. MacLaughlin and M. F. Holick, "Aging decreases the capacity of human skin to produce vitamin D3," Journal of Clinical Investigation, vol. 76, no. 4, pp. 1536-1538, 1985.

[30] M. Holick, L. Matsuoka, and J. Wortsman, "Age, vitamin D, and solar ultraviolet," The Lancet, vol. 2, no. 8671, pp. 1104-1105, 1989.

[31] S. Czernichow, T. Fan, G. Nocea, and S. S. Sen, "Calcium and vitamin D intake by postmenopausal women with osteoporosis in France," Current Medical Research and Opinion, vol. 26 , no. 7, pp. 1667-1674, 2010.

[32] U. Lehmann, F. Hirche, G. I. Stangl, K. Hinz, S. Westphal, and J. Dierkes, "Bioavailability of vitamin D2 and D3 in healthy volunteers, a randomized Placebo-controlled trial," Journal of Clinical Endocrinology \& Metabolism, vol. 98, no. 11, pp. 4339-4345, 2013.

[33] E. Romagnoli, M. L. Mascia, C. Cipriani et al., "Short and long-term variations in serum calciotropic hormones after a single very large dose of ergocalciferol (vitamin D2) or cholecalciferol (vitamin D3) in the elderly," Journal of Clinical Endocrinology \& Metabolism, vol. 93, no. 8, pp. 3015-3020, 2008.

[34] A. Zittermann, J. B. Ernst, J. F. Gummert, and J. Börgermann, "Vitamin D supplementation, body weight and human serum 25-hydroxyvitamin D response: a systematic review," European Journal of Nutrition, vol. 53, no. 2, pp. 367-374, 2014.

[35] R. F. Chun, I. Hernandez, R. Pereira et al., "Differential responses to vitamin D2 and vitamin D3 are associated with variations in free 25-hydroxyvitamin D," Endocrinology, vol. 157, no. 9, pp. 3420-3430, 2016.

[36] M. M. Hammami and A. Yusuf, "Differential effects of vitamin D2 and D3 supplements on 25-hydroxyvitamin D level are dose, sex, and time dependent: a randomized controlled trial," BMC Endocrine Disorders, vol. 17, no. 1, p. 12, 2017.

[37] M. M. Hammami, K. Abuhdeeb, S. Hammami, and A. Yusuf, "Vitamin-D2 treatment-associated decrease in 25(OH)D3 level is a reciprocal phenomenon: a randomized controlled trial," BMC Endocrine Disorders, vol. 17, no. 1, p. 8, 2019.

[38] P. Lips, "Vitamin D deficiency and secondary hyperparathyroidism in the elderly: consequences for bone loss and fractures and therapeutic implications," Endocrine Reviews, vol. 22, no. 4, pp. 477-501, 2001.

[39] J. Pepe, E. Romagnoli, I. Nofroni et al., "Vitamin D status as the major factor determining the circulating levels of parathyroid hormone: a study in normal subjects," Osteoporosis International, vol. 16, no. 7, pp. 805-812, 2005.

[40] K. Samson, H. McCartney, S. Vercauteren, J. Wu, and C. Karakochuk, "Prevalence of vitamin D deficiency varies widely by season in Canadian children and adolescents with sickle cell disease," Journal of Clinical Medicine, vol. 7, no. 2, p. 14, 2018 . 